\title{
Complementary medicine in Germany: a multi-centre cross-sectional survey on the usage by and the needs of patients hospitalized in university medical centers
}

Ann-Kathrin Lederer ${ }^{1,2}$, Alexandra Baginski ${ }^{1}$, Lena Raab', Stefanie Joos ${ }^{3}$, Jan Valentini ${ }^{3}$, Carina Klocke ${ }^{3}$, Yvonne Samstag ${ }^{4}$, Katrin Hübner ${ }^{4}$, Ivana Andreeva ${ }^{4}$, Thomas Simmet ${ }^{5}$, Tatiana Syrovets ${ }^{5}$, Susanne Hafner ${ }^{5}$, Anna Freisinger ${ }^{5}$, Maximilian Andreas Storz ${ }^{1}$ and Roman Huber ${ }^{{ }^{*}}$

\begin{abstract}
Background: The results of recent surveys indicate that more than $50 \%$ of the German population has experience with complementary and alternative medicine (CAM) or uses CAM regularly. This study investigated the CAM usage and CAM-related needs of hospitalized patients at university medical centres in the state of Baden-Württemberg, Germany.

Methods: A multi-centre, paper-based, pseudonymous survey was carried out by the members of the Academic Centre for Complementary and Integrative Medicine. Patients of all ages, regardless of sex, diagnosis and treatment, who were hospitalized in the Department of Cardiology, Gastroenterology, Oncology, Gynaecology or Surgery at the university medical centres in Freiburg, Heidelberg, Tübingen and UIm were eligible for inclusion.

Results: Of the 1275 eligible patients, $67 \%(n=854)$ consented to participate in the survey. Forty-eight percent of the study participants stated that they were currently using CAM. The most frequently used therapies were exercise (63\%), herbal medicine (54\%) and dietary supplements (53\%). Only $16 \%$ of the patients discussed CAM usage with their attending physician. Half of the patients (48\%) were interested in CAM consultations. More than $80 \%$ of the patients desired reliable CAM information and stated that physicians should be better informed about CAM.
\end{abstract}

Conclusions: The frequency of CAM usage and the need for CAM counselling among hospitalized patients at university medical centres in Baden-Württemberg are high. To better meet patients' needs, CAM research and physician education should be intensified.

Trial registration: German Clinical Trial register (DRKS00015445).

Keywords: Complementary therapies, Surveys and questionnaires, Health knowledge, Attitudes, Practice

*Correspondence: roman.huber@uniklinik-freiburg.de

${ }^{1}$ Center for Complementary Medicine, Department of Medicine II, Medical Center - University of Freiburg, Faculty of Medicine, University of Freiburg, Theodor von Frerichs Haus, Sir-Hans-A.-Krebs-Straße, 79106 Freiburg, Germany

Full list of author information is available at the end of the article

\section{Background}

Complementary and alternative medicine (CAM) is commonly used in Europe. According to the results of a European survey published in 2018, every fourth European citizen reported using CAM medicine during the past 12 months before the survey [1]. The usage of CAM was even more frequent in German-speaking

(c) The Author(s) 2021. Open Access This article is licensed under a Creative Commons Attribution 4.0 International License, which permits use, sharing, adaptation, distribution and reproduction in any medium or format, as long as you give appropriate credit to the original author(s) and the source, provide a link to the Creative Commons licence, and indicate if changes were made. The images or other third party material in this article are included in the article's Creative Commons licence, unless indicated otherwise in a credit line to the material. If material is not included in the article's Creative Commons licence and your intended use is not permitted by statutory regulation or exceeds the permitted use, you will need to obtain permission directly from the copyright holder. To view a copy of this licence, visit http://creativecommons.org/licenses/by/4.0/. The Creative Commons Public Domain Dedication waiver (http://creativeco mmons.org/publicdomain/zero/1.0/) applies to the data made available in this article, unless otherwise stated in a credit line to the data. 
countries, with up to $70 \%$ of the German population having experience with CAM [2]. CAM comprises nonmainstream therapeutic approaches, such as anthroposophical medicine, acupuncture, traditional Chinese medicine, homeopathy and herbal medicine. CAM is often used without the prior consultation of a physician $[2,3]$. Research suggests that there is limited communication about CAM between medical staff and patients $[4,5]$. Publications in recent decades reported that every second to third hospitalized patient used CAM, but less than a third of these patients communicated about their CAM usage with their attending physicians [4, 6-10]. The gap between the frequency of CAM usage and communication between patients and physicians emphasizes the need for improvements in medical education about CAM. In 2016, the Academic Centre for Complementary and Integrative Medicine (AZKIM) was founded to promote CAM education and CAM research in Germany. AZKIM is a cooperative centre involving the university medical centres in Freiburg, Heidelberg, Tübingen and Ulm that is financed by the Ministry of Science, Research and Arts of the state of Baden-Württemberg, Germany. The aim of AZKIM is to provide a well-founded knowledge base regarding CAM and integrative medicine for use in basic and clinical research, patient care and training and the continuing education of physicians and medical students. Previous publications showed that many patients desire CAM counselling and physicians who are knowledgeable about CAM, even during a hospital stay, especially as these aspects pertain to a patient-centred and holistic treatment approach $[4,9,11]$. Little is known about CAM use by patients hospitalized in university hospitals. The primary aim of this study was to identify the frequency of CAM usage, the attitudes towards and interest in CAM and the need for CAM counselling among patients hospitalized at the four university medical centres in Freiburg, Heidelberg, Tübingen and Ulm.

\section{Methods}

Between April and December 2018, a multicentre, paperbased, multidisciplinary, pseudonymous cross-sectional study was carried out at the German university medical centres in Freiburg, Heidelberg, Tübingen and Ulm. Patients of all ages, regardless of sex, diagnosis and treatment, who were hospitalized in the Department of Cardiology, Gastroenterology, Oncology, Gynaecology, or Surgery at the university medical centres in Freiburg, Heidelberg, Tübingen and Ulm were eligible for inclusion. Patients had to be able to give their written informed consent before inclusion, to complete the questionnaire on their own and to speak and understand German (at least level B2 according to the European Framework of Reference for Languages [12]). Outpatients and patients in the intensive care unit were excluded.

The study was registered at the German Clinical Trial register (DRKS00015445) and approved by the ethics committee of the University Medical Centre of Freiburg, Germany (EK FR 25/17), before the study was initiated.

\section{Survey}

The questionnaire contained 15 main questions and 6 subordinate questions covering socio-demographic variables such as age, sex and education level; diagnosis; and current quality of life (on a scale from 1 to 10). Additional questions focused on current and previous usage of 21 different CAM approaches (Table 1), knowledge about CAM ("How informed do you consider yourself to be about CAM?"- Patients had to choose between well-informed/informed/poor informed/ not-informed/ indecisive; further questions asked for source of informations), interest in CAM ("Are you interested in CAM consultation regarding your current disease?"- agree or disagree), financing of CAM ("How did you finance CAM usage?" and "How much money did you spend for CAM usage?") and communication about CAM usage ("Do you communicate CAM usage to your attending physician?" - yes or no; further questions asking for reasons and in case of communication, for reaction of the attending physician). In case of CAM usage, motivation for CAM usage (e. g. "I did this/I am going to do this because I want to increase my well-being" -agree or disagree), and in case of non-usage, reasons for non-usage were captured (e. g. "I did not use CAM because I did not need it" - agree or disagree). Furthermore, patients were asked to state their expectations of the attending physicians (e. g. "It is important to me that my attending physician is informed about CAM" - agree or disagree) and their treatment

Table 1 CAM approaches considered in the questionnaire

\begin{tabular}{ll}
\hline CAM approaches & \\
\hline Acupuncture/acupressure & Mental Healing, Mindfulness \\
Anthroposophical medicine & Homeopathy \\
Aroma therapy & Hyperthermia \\
Detoxification & Mistletoe treatment \\
Ayurveda & Osteopathy, Chiropractic \\
Balneotherapy & Herbal medicine \\
Exercise & Traditional Chinese Medicine (TCM) \\
Colonic cleansing, Probiotics & Dietary supplements \\
Diet \& Nutrition & Compresses \\
Relaxing, Mediation & Yoga, Qigong \\
Fasting & \\
\hline
\end{tabular}


needs (e. g. "It is important to me that I am treated in a holistic way" - agree or disagree).

CAM usage was assessed by the following question: "Have you ever used or are you still using at least one of the aforementioned CAM approaches (Table 1) for your current disease?". The need for CAM counselling was assessed by the following question: "Would you like to receive CAM counselling regarding your current disease?"

The questionnaire was modified from two questionnaires, which were previously used by the authors $[13$, 14], and required approximately $30 \mathrm{~min}$ for completion. It was only available in German. The descriptive parameters included age, sex, education level, nationality (German - yes/no), department of hospitalization (cardiology, gastroenterology, oncology, gynaecology or surgery), location of hospital (Freiburg, Heidelberg, Tübingen, Ulm), and oncological or non-oncological treatment. These parameters were also considered factors potentially associated with CAM usage and the need for counselling.

\section{Management of bias}

Patients were asked to answer the questionnaire independently to avoid being influenced by others. Incomplete or formally incorrect (multiple answers for single answer questions) questionnaires were detected by the study staff. Questions were formulated in a neutral manner, and leading questions were avoided. The study staff was encouraged to appear friendly but non-committal to avoid the generation of response tendencies. To prevent language barriers, speaking and understanding German was defined as an inclusion criterion. Recruitment was carried out consecutively, and the questionnaire's topic was not explained in detail before starting.

\section{Statistics}

The sample size needed for multiple regression was calculated. Based on previous publications, a sample size of at least 140 patients was needed for a reliable multiple logistic regression including 7 predictive variables (age, older vs. younger patients, male vs. female patients, department of hospitalization, survey location, nationality and oncologic disease) $[15,16]$. As a response rate of $60 \%$ is recommended for validity, we determined that we needed a sample size of at least 250 patients per location (a total of 1000 patients at 4 locations) [15]. Upon survey completion, data were transferred to a pre-designed table (Microsoft Excel) by three authors. IBM SPSS (Version 27.0) was used for the evaluation. The chi-square test was used to analyse the distribution and compare the characteristics of all analysed categorical variables. $P<0.05$ was considered significant. Unless otherwise stated, the results are given as the percentage of patients who answered a question or as absolute values. Missing data were not imputed.

\section{Results}

A total of 1275 patients were eligible for inclusion. Twothirds of these patients ( $n=854$ patients, 67\%) consented to participate in the survey. Participating patients were treated in the Department of Cardiology (18\%), of Surgery (18\%), of Gynaecology (18\%), of Oncology (23\%) and of Gastroenterology (23\%) (Fig. 1 and Table 2). The mean age of the patients was 58 years (range 15-88 years), and $50 \%$ of patients were female. Further descriptive patient data are shown in Table 2.

("percentage of all patients who answered the question)

\section{Current or previous usage of CAM}

A total of 372 of 777 patients (48\%) stated that they used CAM currently or had used CAM previously for their current disease (cardiology: 39\%, surgery: 44\%, gynaecology: $47 \%$, oncology: $52 \%$, gastroenterology: $54 \%)$. CAM usage depended on the survey location (Freiburg: 56\%, Heidelberg: 51\%, Tübingen: 46\%, Ulm: $36 \%$ ) and nationality (German: $49 \%$, other: $28 \%$ ) and department of hospitalization (cardiology: 38\%, gastroenterology: 54\%, oncology: $52 \%$, gynaecology: $47 \%$, surgery: $44 \%$, Table 3 ). Further factors, which might affect current or previous usage of CAM, are shown in Table 3.

From the list of 21 CAM approaches (Table 1), exercise (63\% of 834 patients), herbal medicine (56\% of 843 patients), intake of dietary supplements (54\% of 834 patients), balneotherapy ( $45 \%$ of 824 patients), relaxation therapy ( $43 \%$ of 840 patients) and homeopathy (43\% of 835 patients) were the most frequently used (Fig. 2).

Patients who stated that they currently used CAM were asked about their reasons for using CAM. Patients stated that they used CAM to increase their well-being $(87 \%$ of 437 patients), to positively affect their health ( $86 \%$ of 426 patients) or to actively treat their disease (86\% of 437 patients). CAM usage was motivated by a favourable attitude towards holistic therapy in almost $60 \%$ of the 435 responding patients. One-third of the patients $(29 \%$ of 430 patients) stated that the lack of success of conventional therapy was the reason for their usage of CAM.

Overall, 405 of 777 patients (52\%) reported that they did not currently use CAM. The most common reasons given were the lack of CAM counselling (50\%), lack of reliable CAM information (42\%) and no need for CAM (42\%). One-third of these patients (32\%) 


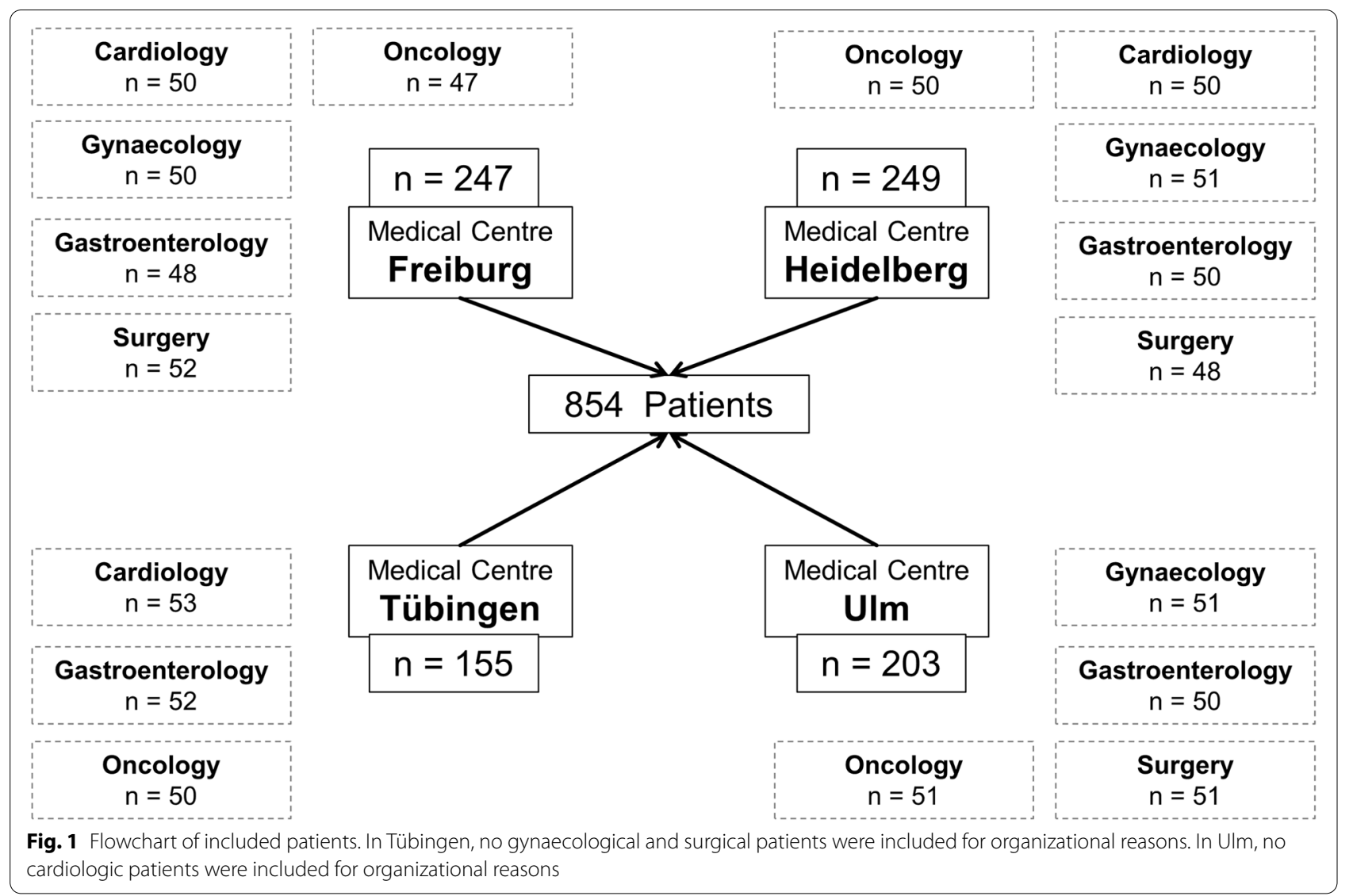

questioned the efficacy of CAM, and another onethird (34\%) feared interactions with their conventional therapy. Only a few patients indicated that attending physicians $(7 \%)$ or friends (6\%) discouraged them from using CAM.

\section{Demands and expectations of attending physicians}

A total of 382 patients (48\%) out of the 795 responding patients desired CAM counselling for their current disease (responded "yes" when they were asked about their need for CAM counselling). Furthermore, 225 patients (26\%) stated "I don't know", and 188 patients (24\%) stated they did not need CAM counselling. The results of multiple logistic regression are shown in Table 4.

The need for reliable CAM information was reported by more than $80 \%$ of the 814 responding patients. Nearly $80 \%$ of these patients stated that attending physicians should be informed about CAM. University CAM research was desired by nearly $80 \%$ of the 816 responding patients. More than half of the patients felt poorly informed (39\% of 781 patients) or completely uninformed about CAM (21\%). Sources of information about CAM are shown in Table 5.
Only $16 \%$ of the total of 823 responding patients stated that they had communicated their interest in or use of CAM to their attending physician. More than one-third of the patients $(39 \%, n=45)$ who had communicated about CAM stated that their physicians supported their use of CAM, and $30 \%$ of the patients reported that CAM was recommended by the attending physicians. Only $16 \%(n=18)$ reported that their physicians had a negative attitude towards CAM, and $33 \%(n=38)$ questioned the efficacy of CAM. Among the patients who did not communicate about CAM with their attending physician $(n=689), 26 \%$ stated $(n=116)$ that the reason was that they were afraid of a negative response from their physician. Half of the responding patients $(51 \%, n=250)$ indicated that they did not have time for a conversation about CAM.

\section{Financing of CAM}

A total of 428 patients gave information about CAM financing. A total of $72 \%$ paid for CAM themselves. Only $20 \%$ of the patients stated that their statutory health insurance had covered the CAM costs. An 
Table 2 Overview of descriptive patient data $(n=854)$. All values were rounded to whole numbers

\begin{tabular}{|c|c|c|c|}
\hline & $\mathbf{n}$ & $\% *$ & Not clarified (n) \\
\hline \multicolumn{4}{|l|}{ Department of treatment } \\
\hline Cardiology & 153 & $18 \%$ & \\
\hline Gastroenterology & 200 & $23 \%$ & \\
\hline Gynaecology & 152 & $18 \%$ & 0 \\
\hline Oncology & 198 & $23 \%$ & \\
\hline Surgery & 151 & $18 \%$ & \\
\hline \multicolumn{4}{|l|}{ Sex } \\
\hline Female & 417 & $50 \%$ & 13 \\
\hline Male & 424 & $50 \%$ & \\
\hline \multicolumn{4}{|l|}{ Education level } \\
\hline No graduation & 15 & $2 \%$ & 35 \\
\hline Short-term secondary school ("Hauptschule") & 192 & $23 \%$ & \\
\hline Elementary school ("Volksschule") & 30 & $4 \%$ & \\
\hline Vocational school ("Berufsschule") & 12 & $2 \%$ & \\
\hline School for handicapped children & 1 & $0 \%$ & \\
\hline Intermediate-term secondary high school ("Mittlere Reife") & 256 & $31 \%$ & \\
\hline High school ("Abitur") & 105 & $13 \%$ & \\
\hline University & 208 & $25 \%$ & \\
\hline \multicolumn{4}{|l|}{ Nationality } \\
\hline German & 787 & $94 \%$ & 16 \\
\hline Italian & 9 & $1 \%$ & \\
\hline Turkish & 7 & $1 \%$ & \\
\hline Romanian & 3 & $1 \%$ & \\
\hline Other & 32 & $3 \%$ & \\
\hline$>60$ years of age & 439 & $52 \%$ & 15 \\
\hline$<60$ years of age & 400 & $48 \%$ & \\
\hline Cancer & 332 & $39 \%$ & 5 \\
\hline
\end{tabular}

average amount of $1220 \pm 2857 €$ was spent on current CAM treatment. The high cost was stated as the reason for not using CAM by $22 \%$ of patients who did not use CAM. On average, more than $80 \%$ of the 819 responding patients wanted the cost of CAM to be covered by statutory health insurance.

\section{Discussion}

The results of our survey emphasize the relevance of CAM in the context of university medical centre inpatient treatment, as nearly $50 \%$ of the patients were using CAM. The most frequently used methods were physical exercise, herbal medication and dietary supplements. Furthermore, nearly half of the patients were clearly interested in CAM counselling and thought that physicians should be informed about CAM.

\section{Limitations and strengths}

The strength of our survey was the response rate of $67 \%$, as a response rate of approximately $60 \%$ is recommended based on recent research to avoid bias [15]. However, selection bias could not be ruled out since it is could be assumed that patients interested in CAM are also more interested in and compliant with participating in a CAMrelated survey. The study was only carried out in BadenWürttemberg, implying limited generalizability of the results to other regions in Germany as well as to other countries all over the world.

\section{Selection of patients by CAM financing and comparison with CAM usage in other surveys}

Baden-Württemberg is one of the wealthiest regions in Germany [16]. More than two-thirds of the patients financed CAM privately, and CAM treatments are expensive. Thus, many patients with limited means are probably not able to afford CAM. A comparable survey performed in 2018 at the medical centre in Chemnitz (a non-university maximum-care hospital in Eastern Germany) by our research group showed a lower frequency of current CAM usage of $30 \%$ in orthopaedic and 
Table 3 Factors affecting answering the question "Have you ever used before or are you still using at least one of the aforementioned CAM approaches regarding your current disease?"

\begin{tabular}{|c|c|c|c|c|c|c|c|}
\hline \multirow[t]{2}{*}{ Parameter } & \multirow[t]{2}{*}{ Distribution } & \multirow{2}{*}{$\begin{array}{l}\text { Regression } \\
\text { coefficient }\end{array}$} & \multirow[t]{2}{*}{ Standard error } & \multirow[t]{2}{*}{$p$} & \multirow[t]{2}{*}{ Odds ratio } & \multicolumn{2}{|c|}{ 95\%-Confidence Interval } \\
\hline & & & & & & Lower & Upper \\
\hline Age & - & 0.011 & 0.009 & 0.208 & 1.011 & 0.994 & 1.028 \\
\hline$<60$ years of age & $49 \%$ & -0.079 & 0.260 & 0.761 & 0.924 & 0.555 & 1.538 \\
\hline$>60$ years of age & $51 \%$ & Reference & Reference & Reference & Reference & Reference & Reference \\
\hline \multicolumn{8}{|l|}{ Sex } \\
\hline Male & $49 \%$ & 0.249 & 0.173 & 0.149 & 1.283 & 0.915 & 1.799 \\
\hline Female & $51 \%$ & Reference & Reference & Reference & Reference & Reference & Reference \\
\hline \multicolumn{8}{|l|}{ Department } \\
\hline Cardiology & $17 \%$ & 0.740 & 0.254 & 0.004 & 2.095 & 1.273 & 3.450 \\
\hline Gastroenterology & $23 \%$ & Reference & Reference & Reference & Reference & Reference & Reference \\
\hline Gynaecology & $19 \%$ & 0.511 & 0.271 & 0.059 & 1.667 & 0.981 & 2.833 \\
\hline Oncology & $24 \%$ & 0.130 & 0.245 & 0.595 & 1.139 & 0.704 & 1.843 \\
\hline Surgery & $17 \%$ & 0.435 & 0.252 & 0.084 & 1.545 & 0.943 & 2.530 \\
\hline \multicolumn{8}{|l|}{ Survey location } \\
\hline Freiburg & $31 \%$ & -0.302 & 0.200 & 0.130 & 0.739 & 0.500 & 1.093 \\
\hline Heidelberg & $27 \%$ & Reference & Reference & Reference & Reference & Reference & Reference \\
\hline Tübingen & $16 \%$ & 0.218 & 0.249 & 0.383 & 1.243 & 0.763 & 2.027 \\
\hline Ulm & $26 \%$ & 0.640 & 0.216 & 0.003 & 1.896 & 1.241 & 2.898 \\
\hline \multicolumn{8}{|l|}{ Cancer } \\
\hline Yes & $40 \%$ & -0.007 & 0.191 & 0.969 & 0.993 & 0.683 & 1.1443 \\
\hline No & $60 \%$ & Reference & Reference & Reference & Reference & Reference & Reference \\
\hline \multicolumn{8}{|l|}{ Nationality } \\
\hline German & $94 \%$ & 0.915 & 0.347 & 0.008 & 2.496 & 1.264 & 4.927 \\
\hline Other & $6 \%$ & Reference & Reference & Reference & Reference & Reference & Reference \\
\hline
\end{tabular}

Multiple logistic regression (Nagelkerke $R^{2}=0.084 ; \mathrm{H}=0.336$ ), highest sample-size group was chosen as reference. Only patients for whom a complete data set was available were evaluated ( $n=762$ ). Patients in Heidelberg used CAM more frequently than patients from Ulm (51 vs. $36 \%)$. The CAM usage was significantly more frequent in patients of German nationality than in patients of other nationalities (49 vs. 28\%). Patients hospitalized at the department of gastroenterology had a higher CAM usage frequency than cardiologic patients (54 vs. $39 \%$ ).

trauma patients [4]. Chemnitz is a low-income region compared to Baden-Württemberg. Reimbursement for CAM has been discussed for decades in medical journals [17-19]. In 2004, most herbal medications were removed from the statutory health insurance catalogue of reimbursable medications in Germany for financial reasons. In Switzerland, the CAM costs incurred by $60 \%$ of the population are covered by additional insurance [20]. The majority of patients in our survey stated that effective CAM approaches should be covered by health insurance, which was also reported in Chemnitz and is confirmed by the high proportion of patients with additional insurance in Switzerland. Nevertheless, the interest in CAM and usage of CAM were similar in the study performed in Chemnitz and this survey, emphasizing the high level of interest in CAM among patients in Germany. A survey of inpatient internal medicine patients carried out in Switzerland in 2014 showed that $32 \%$ had used CAM during or 2 months prior to hospitalization, and herbal medicine was the most common modality [7]. Similarly, Schieman et al. found a preference for herbal medicine, with an overall frequency of CAM usage of $27 \%$ in surgical patients in Canada [6]. In addition, dietary supplements were frequently used, which is in accordance with the results of our study and the study performed in Chemnitz [4]. Teo et al. reported a CAM usage frequency of $44 \%$ in hospitalized patients with cardiovascular diseases in Singapore in 2016 [8]. The CAM approaches in that study (TCM and Jamu, a traditional Indonesian herbal medicine) differed from ours, which can be explained by cultural differences, but again, herbal medication was the predominant modality. Other German surveys including non-hospitalized patients with chronic illnesses such as inflammatory bowel diseases, multiple sclerosis or cancer reported a CAM usage frequency of up to $72 \%$, with the predominant use of dietary supplements and herbal medicine [21-25]. 


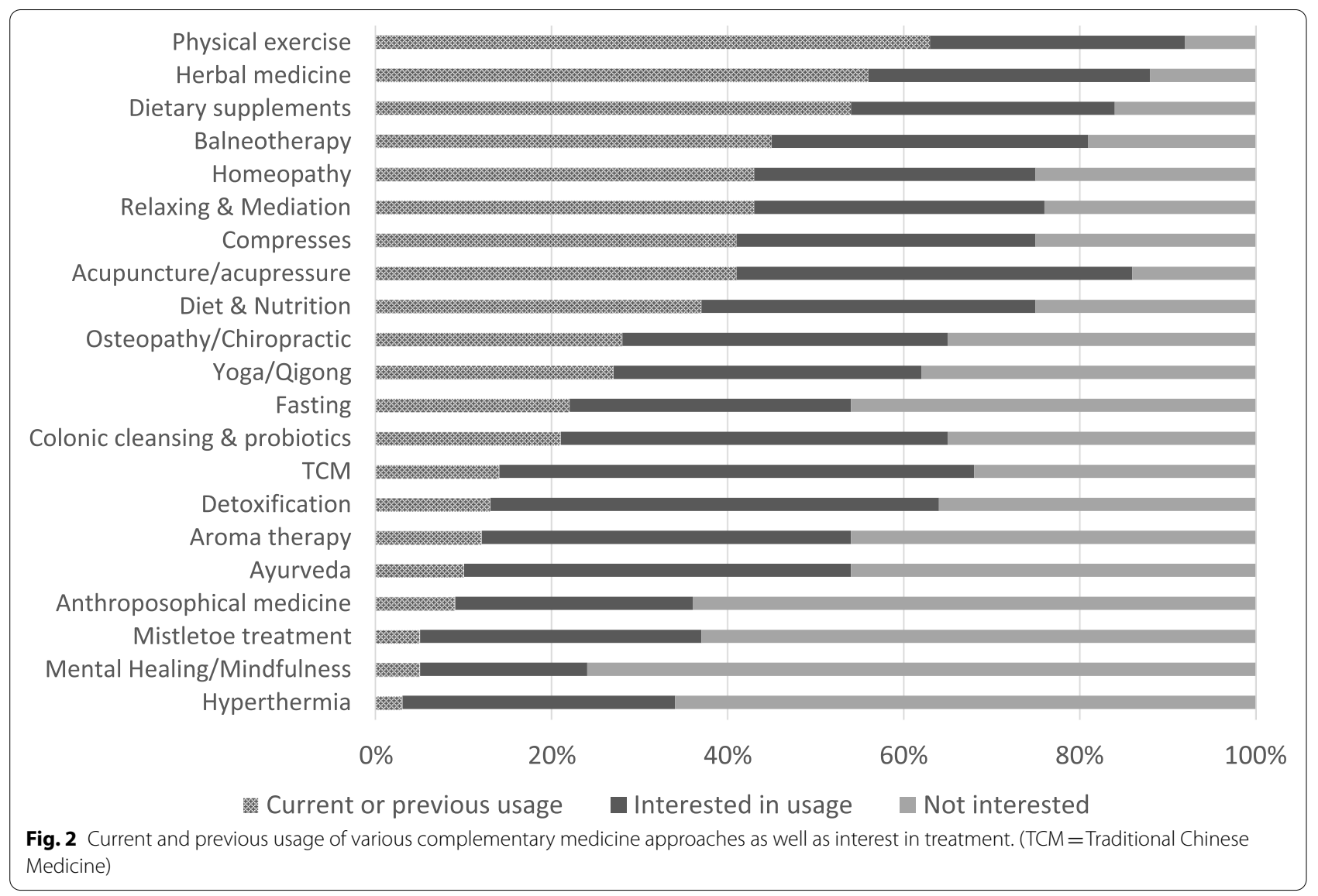

\section{Non-communication about CAM}

Notably, only a minority (16\%) of patients stated communicating about CAM with their attending physician. Other recent studies reported that up to one-third of patients communicated about their CAM usage with their attending physician. Communication differs between inpatients and outpatients and depends on the attending physician's specialization $[4,9,11$, $26-28]$. Kilper et al. reported that only $15 \%$ of inpatient orthopaedic and trauma patients in Germany indicated their use of CAM [4]. In a Hungarian study, $13 \%$ of inpatient surgical patients told their attending physician about their CAM interest [9]. A further survey in Israel showed that only $12 \%$ of patients communicated about CAM with clinicians, whereas a significantly larger proportion (50\%) communicated with general practitioners [29]. In an American survey of patients undergoing radiation, only $12 \%$ of patients stated a conversation about CAM usage with their radiologist [30]. The results of a German online survey of an oncological self-help group showed that 28,24 and $10 \%$ of the patients communicated about CAM with oncologists, general practitioners and other physicians, respectively [11]. The lack of communication poses risks, as potential interactions between herbal medicines or dietary supplements and conventional therapies might be missed. Improvements are needed in communication about CAM.

\section{The demand for reliable information about CAM and CAM informed physicians}

As shown in our study, patients are interested in reliable information about CAM [4]. Patients in our study, as well as in previous publications, felt poorly informed about CAM [22] and wanted to receive combined or holistic treatment with CAM and conventional medicine [2, $4,23]$. More than half of the patients in our trial stated that they had an interest in CAM counselling, and more than $80 \%$ wished that attending physicians knew about CAM. This was also reported in other surveys [4, 9-11]. Furthermore, patients want improved medical education and research about CAM. Physicians should be informed about CAM, not only to improve patient safety but also to ensure quality and promote patient-centred treatment. 
Table 4 Factors affecting answering the question "Would you like to have CAM counselling regarding your current disease?"

\begin{tabular}{|c|c|c|c|c|c|c|c|}
\hline \multirow[t]{2}{*}{ Parameter } & \multirow[t]{2}{*}{ Distribution } & \multirow{2}{*}{$\begin{array}{l}\text { Regression } \\
\text { coefficient }\end{array}$} & \multirow[t]{2}{*}{ Standard error } & \multirow[t]{2}{*}{ p } & \multirow[t]{2}{*}{ Odds ratio } & \multicolumn{2}{|c|}{ 95\%-Confidence Interval } \\
\hline & & & & & & Lower & Lower \\
\hline Age & - & 0.009 & 0.011 & 0.383 & 1.010 & 0.988 & 1.031 \\
\hline$<60$ years of age & $49 \%$ & -0.289 & 0.325 & 0.787 & 0.749 & 0.396 & 1.418 \\
\hline$>60$ years of age & $51 \%$ & Reference & Reference & Reference & Reference & Reference & Reference \\
\hline \multicolumn{8}{|l|}{ Sex } \\
\hline Male & $47 \%$ & 0.612 & 0.218 & 0.005 & 1.845 & 1.204 & 2.827 \\
\hline Female & $53 \%$ & Reference & Reference & Reference & Reference & Reference & Reference \\
\hline \multicolumn{8}{|l|}{ Department } \\
\hline Cardiology & $16 \%$ & 0.910 & 0.316 & 0.004 & 2.483 & 1.337 & 4.613 \\
\hline Gastroenterology & $24 \%$ & Reference & Reference & Reference & Reference & Reference & Reference \\
\hline Gynaecology & $20 \%$ & 0.659 & 0.350 & 0.059 & 1.933 & 0.947 & 3.838 \\
\hline Oncology & $21 \%$ & 0.250 & 0.328 & 0.446 & 1.285 & 0.675 & 2.445 \\
\hline Surgery & $19 \%$ & 0.277 & 0.300 & 0.357 & 1.319 & 0.732 & 2.376 \\
\hline \multicolumn{8}{|l|}{ Survey location } \\
\hline Freiburg & $29 \%$ & 0.608 & 0.265 & 0.022 & 1.837 & 1.093 & 3.088 \\
\hline Heidelberg & $28 \%$ & Reference & Reference & Reference & Reference & Reference & Reference \\
\hline Tübingen & $15 \%$ & 0.471 & 0.329 & 0.152 & 1.602 & 0.840 & 3.054 \\
\hline Ulm & $28 \%$ & 0.981 & 0.278 & $<0.001$ & 2.668 & 1.548 & 4.598 \\
\hline \multicolumn{8}{|l|}{ Cancer } \\
\hline Yes & $39 \%$ & -0.358 & 0.245 & 0.144 & 0.699 & 0.432 & 1.130 \\
\hline No & $61 \%$ & Reference & Reference & Reference & Reference & Reference & Reference \\
\hline \multicolumn{8}{|l|}{ Nationality } \\
\hline German & $93 \%$ & 0.311 & 0.348 & 0.373 & 1.364 & 0.689 & 2.701 \\
\hline Other & $7 \%$ & Reference & Reference & Reference & Reference & Reference & Reference \\
\hline
\end{tabular}

Multiple logistic regression (Nagelkerke $R^{2}=0.121 ; \mathrm{H}=0.046$ ), highest sample-size group was chosen as reference. Only patients for whom a complete data set was available and who answered "yes" or "no" were evaluated $(n=562)$. Female patients stated a higher need for CAM counselling (73 vs. $60 \%)$. Patients hospitalized at the department of gastroenterology had a higher need for CAM counselling than cardiologic patients (72 vs. 51\%). Patients in Heidelberg stated a higher need for CAM counselling (77\%) than patients in Freiburg (64\%) and Ulm (60\%).

Table 5 Overview of CAM information sources for all patients $(n=854)$

\begin{tabular}{ll}
\hline Information source & $\begin{array}{l}\text { Percentage } \\
\text { of positive } \\
\text { responses (n) }\end{array}$ \\
\hline General practitioner & $47 \%(404)$ \\
Medical specialists & $25 \%(214)$ \\
Clinicians & $16 \%(136)$ \\
Pharmacists & $16 \%(135)$ \\
Non-medical practitioners & $13 \%(113)$ \\
Nurses & $7 \%(56)$ \\
Internet & $46 \%(393)$ \\
Brochures & $29 \%(251)$ \\
Books & $22 \%(187)$ \\
Magazines & $21 \%(178)$ \\
Conferences & $3 \%(29)$ \\
Friends and family & $23 \%(200)$ \\
Self-help group & $7 \%(56)$ \\
\hline
\end{tabular}

\section{Conclusion}

This study shows the relevance of CAM at university medical centres in the state of Baden-Württemberg, Germany. The frequency of CAM usage was high. Furthermore, the results of our study emphasize a high level of the need for CAM counselling and desire for the attending physicians to be informed about CAM. Communication about CAM is still poor, indicating the need to actively ask patients about their CAM usage. To facilitate patient-centred treatment and ensure treatment safety and quality, physicians should be better informed about CAM.

\section{Abbreviations \\ AZKIM: Akademisches zentrum komplementäre und integrative medizin (academic center for complementary and integrative medicine); CAM: Com- plementary medicine; TCM: Traditional Chinese medicine.}

\section{Acknowledgments}

Our heartfelt thank you to all of the participating patients!

\section{Authors' contributions}

Study conceptualization and design: SJ, JV, YS, KH, TSi, TSy, SH, RH. Development of questionnaire: SJ, JV, YS, KH, RH. Data collection: AKL, AB, LR, CK, KH, 
IA, SH, AF. Data entering: AKL, AB, LR. Interpretation and analysis of results: AKL, SJ, JV, YS, KH, TSi, TSY, SH, MAS, RH. Drafting of manuscript: AKL, RH. Review and editing of manuscript: SJ, JV, KH, YS, TSi, TSy, SH, AF, MAS. Supervision of study: SJ, JV, KH, YS, TSi, TSy, RH. The author(s) read and approved the final manuscript.

\section{Funding}

Open Access funding enabled and organized by Projekt DEAL. The Ministry of Science, Research and Arts of the state Baden-Württemberg, Germany, financed the Academic Centre for Complementary and Integrative Medicine (AZKIM), otherwise the study was financed by institutional resources.

\section{Availability of data and materials}

The datasets used and analysed during the current study are available from the corresponding author on reasonable request.

\section{Declarations}

\section{Ethics approval and consent to participate}

Study was approved by ethical committee of the University Medical Centre of Freiburg, Germany (EK FR 25/17). For participation, patients had to give written informed consent before inclusion.All methods were performed in accordance with the Declaration of Helsinki.

\section{Consent for publication}

Not applicable.

\section{Competing interests}

None. The authors have no conflicts of interest or financial ties to disclose.

\begin{abstract}
Author details
${ }^{1}$ Center for Complementary Medicine, Department of Medicine II, Medical Center - University of Freiburg, Faculty of Medicine, University of Freiburg, Theodor von Frerichs Haus, Sir-Hans-A.-Krebs-Straße, 79106 Freiburg, Germany. ${ }^{2}$ Chirurgische Klinik, Evangelisches Diakoniekrankenhaus, Freiburg, Germany. ${ }^{3}$ Institute for General Practice and Interprofessional Care, University Hospital Tübingen, Tübingen, Germany. ${ }^{4}$ Institute of Immunology, Section Molecular Immunology, University of Heidelberg, Heidelberg, Germany. Institute of Pharmacology of Natural Products \& Clinical Pharmacology, Ulm University, Ulm, Germany.
\end{abstract}

Received: 4 May 2021 Accepted: 8 November 2021

Published online: 23 November 2021

\section{References}

1. Kemppainen LM, Kemppainen TT, Reippainen JA, Salmenniemi ST, Vuolanto PH. Use of complementary and alternative medicine in Europe: health-related and sociodemographic determinants. Scand J Public Health. 2018;46:448-55. https://doi.org/10.1177/1403494817733869.

2. Institut für Demoskopie Allensbach. Naturheilmittel 2010 - Ergebnisse einer bevölkerungsrepräsentativen Befragung. 2010;:23. http://www. ifd-allensbach.de/uploads/tx_studies/7528_Naturheilmittel_2010.pdf. Accessed 9 May 2017.

3. Horneber M, Bueschel G, Dennert G, Less D, Ritter E, Zwahlen M. How many cancer patients use complementary and alternative medicine: a systematic review and metaanalysis. Integr Cancer Ther. 2012;11:187203. https://doi.org/10.1177/1534735411423920.

4. Kilper A, Müller A, Huber R, Reimers N, Schütz L, Lederer A-K. Complementary medicine in orthopaedic and trauma surgery: a crosssectional survey on usage and needs. BMJ Open. 2020;10:e037192. https://doi.org/10.1136/bmjopen-2020-037192.

5. Bauer BA, Townsend KM, Cutshall SM, Hazelton JF, Mahapatra S, Meek AM, et al. Advanced practice providers' knowledge, attitudes, and utilization of complementary and integrative medicine at an Academic Medical Center. Altern Ther Health Med. 2020;26:8-16 http://www. ncbi.nlm.nih.gov/pubmed/32663179.

6. Schieman C, Rudmik LR, Dixon E, Sutherland F, Bathe OF. Complementary and alternative medicine use among general surgery, hepatobiliary surgery and surgical oncology patients. Can J Surg. 2009;52:422-6 http://www.pubmedcentral.nih.gov/articlerender.fcgi? artid=2769094\&tool=pmcentrez\&rendertype=abstract.

7. Ducrest I, Marques-Vidal P, Faouzi M, Burnand B, Waeber G, Rodondi P-Y. Complementary medicine use among general internal medicine inpatients in a Swiss university hospital. Int J Clin Pract. 2017;71:e12952. https://doi.org/10.1111/ijcp.12952.

8. Teo TY, Yap J, Shen T, Yeo KK. Complementary and alternative medicine use amongst patients with cardiovascular disease in Singapore. BMC Complement Altern Med. 2016;16:446. https://doi.org/10.1186/ s12906-016-1430-4.

9. Soós SÁ, Jeszenői N, Darvas K, Harsányi L. Nem konvencionális gyógymódok használata sebészeti betegek között. Orv Hetil. 2016;157:1483-8. https://doi.org/10.1556/650.2016.30543.

10. Huber R, Koch D, Beiser I, Zschocke I, Luedtke R. Experience and attitudes towards CAM--a survey of internal and psychosomatic patients in a German university hospital. Altern Ther Health Med. 2004;10:32-6 http://www.ncbi.nlm.nih.gov/pubmed/14727497.

11. Bauer F, Schmidt T, Eisfeld H, Dubois C, Kastrati K, Hochhaus A, et al. Information needs and usage of complementary and alternative medicine in members of a German self-help group for gastrointestinal stroma tumours, sarcoma, and renal cancer. Complement Ther Med. 2018;41:105-10. https://doi.org/10.1016/j.ctim.2018.09.008.

12. Council of Europe. Gemeinsamer europäischer Referenzrahmen für Sprachen: Lernen, lehren, beurteilen. 2001. http://www.goethe.de/z/ 50/commeuro/deindex.htm. Accessed 15 Aug 2020.

13. Huber R, Lüdtke R, Beiser I, Koch D. Coping strategies and the request for a consultation on complementary and alternative medicine - a cross-sectional survey of patients in a psychosomatic and three medical Departments of a German University hospital. Forsch Komplementärmed Res Complement Med. 2004;11:207-11. https://doi.org/10. $1159 / 000080556$

14. KOKON. KOKON - Kompetenznetz Komplementärmedizin in der Onkologie. https://www.kompetenznetz-kokon.de/. Accessed 28 Aug 2019.

15. Draugalis JR, Coons SJ, Plaza CM. Best practices for survey research reports: a synopsis for authors and reviewers. Am J Pharm Educ. 2008;72:11. https://doi.org/10.5688/aj720111.

16. Statistisches Bundesamt. Volkswirtschaftliche Gesamtrechnung der Länder 2020. https://www.statistikportal.de/de/vgrdl/ergebnisse-laend erebene. Accessed 18 Mar 2021.

17. Witt CM. Komplementärmedizin: Weitere Forschung ist die Basis für Integration in die Versorgung. Dtsch Arztebl. 2009;106:1786-9.

18. Whedon J, Tosteson TD, Kizhakkeveettil A, Kimura MN. Insurance reimbursement for complementary healthcare services. J Altern Complement Med. 2017;23:264-7. https://doi.org/10.1089/acm.2016.0369.

19. Herman PM, Poindexter BL, Witt CM, Eisenberg DM. Are complementary therapies and integrative care cost-effective? A systematic review of economic evaluations. BMJ Open. 2012;2:e001046. https://doi.org/ 10.1136/bmjopen-2012-001046.

20. Klein SD, Torchetti L, Frei-Erb M, Wolf U. Usage of complementary medicine in Switzerland: results of the Swiss health survey 2012 and development since 2007. PLoS One. 2015;10:e0141985. https://doi.org/ 10.1371/journal.pone.0141985.

21. Drozdoff L, Klein E, Kiechle M, Paepke D. Use of biologically-based complementary medicine in breast and gynecological cancer patients during systemic therapy. BMC Complement Altern Med. 2018;18:259. https://doi.org/10.1186/s12906-018-2325-3.

22. Joos S, Rosemann T, Szecsenyi J, Hahn EG, Willich SN, Brinkhaus B. Use of complementary and alternative medicine in Germany - a survey of patients with inflammatory bowel disease. BMC Complement Altern Med. 2006;6:19. https://doi.org/10.1186/1472-6882-6-19.

23. Langhorst J, Anthonisen IB, Steder-Neukamm U, Lüdtke R, Spahn G, Michalsen A, et al. Amount of systemic steroid medication is a strong predictor for the use of complementary and alternative medicine in patients with inflammatory bowel disease. Inflamm Bowel Dis. 2005;11:287-95. https://doi.org/10.1097/01.MIB.0000160771.71328.6c.

24. Schwarz S, Knorr C, Geiger H, Flachenecker P. Complementary and alternative medicine for multiple sclerosis. Mult Scler J. 2008;14:1113-9. https://doi.org/10.1177/1352458508092808. 
25. Hierl M, Pfirstinger J, Andreesen R, Holler E, Mayer S, Wolff D, et al. Complementary and alternative medicine: a clinical study in 1,016 hematology/oncology patients. Oncology. 2017;93:157-63. https://doi. org/10.1159/000464248.

26. Lazarou R, Heinrich M. Herbal medicine: who cares? The changing views on medicinal plants and their roles in British lifestyle. Phyther Res 2019::ptr.6431. doi:https://doi.org/10.1002/ptr.6431.

27. Wortmann JK, Bremer A, Eich H, Wortmann HK, Schuster A, Fühner J, et al. Use of complementary and alternative medicine by patients with cancer: a cross-sectional study at different points of cancer care. Med Oncol. 2016:33:78. https://doi.org/10.1007/s12032-016-0790-4.

28. Zahn R, Perry N, Perry E, Mukaetova-Ladinska EB. Use of herbal medicines: pilot survey of UK users' views. Complement Ther Med. 2019;44:83-90. https://doi.org/10.1016/j.ctim.2019.02.007.
29. Azaz-Livshits T, Muszkat M, Levy M. Use of complementary alternative medicine in patients admitted to internal medicine wards. Int J Clin Pharmacol Ther. 2002;40:539-47. https://doi.org/10.5414/CPP40539.

30. Ge J, Fishman J, Vapiwala N, Li SQ, Desai K, Xie SX, et al. Patient-physician communication about complementary and alternative medicine in a radiation oncology setting. Int J Radiat Oncol. 2013;85:e1-6. https://doi. org/10.1016/j.ijrobp.2012.08.018.

\section{Publisher's Note}

Springer Nature remains neutral with regard to jurisdictional claims in published maps and institutional affiliations.
Ready to submit your research? Choose BMC and benefit from:

- fast, convenient online submission

- thorough peer review by experienced researchers in your field

- rapid publication on acceptance

- support for research data, including large and complex data types

- gold Open Access which fosters wider collaboration and increased citations

- maximum visibility for your research: over $100 \mathrm{M}$ website views per year

At BMC, research is always in progress.

Learn more biomedcentral.com/submissions 